\title{
Whose (Transformative) Reality Counts? A Critical Review of the Transformative Social Protection Framework
}

\author{
Ken Aoo, Saul Butters, Nicolina Lamhauge, \\ Rebecca Napier-Moore and Yuko Ono
}

\begin{abstract}
1 Introduction
Devereux and Sabates-Wheeler's Transformative Social Protection framework steps into new territory by addressing not only transitory, shock-induced poverty, but also chronic and structural poverty that endures both before and after a crisis. The framework then, is significantly broader than more common resource transfer models. Moving beyond economic safety nets, the Transformative Social Protection (TSP) approach wants to address social inequalities and abuses of power. Further, Devereux and Sabates-Wheeler (2004) recognise that in practice, neither the market nor the state deliver protective measures infallibly, and their model therefore reintroduces communal and collective sources of protection.

The framework's laudable strengths, however, raise questions: Who is determining the agenda of transformation? Is the model prepared to deal with any unintended consequences of that transformation? It must be recognised that real and deep transformation is necessarily long term. Who is going to fund a commitment of that kind, and what re-election oriented politician will support it? Will TSP be another development fad that results in the proliferation of ever-more uncoordinated projects? Finally, is its breadth too ambitious?
\end{abstract}

\section{Power and decision-making}

As Robert Chambers noted in Whose Reality Counts? 'poor people's realities [are] local, complex, diverse dynamic and unpredictable' (Chambers 1997: 162). Setting a sweeping transformative agenda for the poor could be patronising and is arguably an assertion of outside (neocolonial?) power. Doing so might tread on sovereignty, as well as on the community base that Devereux and SabatesWheeler want to reinvigorate as a tool for protection. The development industry's 'participation' champions rightly advocate for the poor to have decision-making power, especially over political agendas that affect their lives.

The transformative part of the TSP framework includes legislative changes to eliminate child labour or to protect against discrimination of ethnic minorities or disabled people. TSP's transformative component also includes sensitisation campaigns 'to transform public attitudes and behaviour' about HIV/AIDS, for instance. But what if parts of that agenda are contested by the people who are meant to benefit from it? Child labour is a classic case where 'western' norms are sometimes opposed, and the voices of those directly affected by its elimination often say that the ban harms their households. Who decides at what age it is okay to work? And, does family farm labour count?

Transformation can also be messy. TSP is prepared to catalyse that transformation, but it may also need to be prepared to deal with unintended results. Sometimes, as in the example above, livelihoods might be harmed by a ban on child labour. Another unintended effect might be in the political process itself. What if, for example, political elites co-opt and alter the 'transformative' agendas to serve their own purposes? New political relations and sources of 
power are introduced through all processes of transformation.

Involvement in agenda-setting means involvement in politics, which as we saw above, can be a powerfully patronising process - as well as one that can be manipulated. But maybe that manipulation is a reclamation of control that makes it less patronising?

Involvement in politics has implications for the humanitarian principle of neutrality - a line which development agendas often cross, but which most humanitarian agencies guardedly stay behind. Recent publications from the Humanitarian Policy Group at the Overseas Development Institute (ODI) have reflected on how social protection and humanitarian relief are linked. Longley et al. (2006) recognise that the transformative approach is necessary in order to address political and structural inequalities, but they find that its application is problematic, since it inevitably entails taking positions and becoming politically engaged, challenging the humanitarian principle of neutrality. They remain conscious of the access that neutrality gives relief organisations to otherwise inaccessible conflict zones, and they argue that taking a political position might only be possible with the establishment of a legitimate government as well as a situation of peace and security. The combination of relief and social protection, they say, is 'largely uncharted territory'. Others, like Jeff Crisp from UNHCR (Crisp 2001), talk about a 'reliefdevelopment gap'. Devereux and Sabates-Wheeler's breadth in scope is a good beginning in thinking about how to bridge that gap. TSP moves from 'protective' relief from deprivation; to 'preventative' averting of that deprivation; to 'promotive' enhancement of incomes and capabilities; and finally to 'transformative', long-term development. But Devereux and SabatesWheeler might consider, or at least make explicit, implications for the neutrality principle.

\section{Community and its 'dark side'}

Devereux and Sabates-Wheeler integrate an important self-critique of the TSP framework into their discussion of the community's role in providing 'non-formal social safety nets'. They are right to incorporate the reality that market and state models have limits. There are limits in terms of reaching rural areas because of a persistent urban bias; limits in providing social insurance because developing countries lack a large formal economy; limits in providing private insurance because credit and insurance markets are often underdeveloped, and so on.

The TSP model tries to fill this gap with non-formal systems of kinship, traditional reciprocity and dependence. But calling on these institutions may be a little romantic. Do not these non-formal systems often include systemic marginalisation? What if the community abandons and sidelines some people? Devereux and Sabates-Wheeler recognise this when pointing to the 'dark side' of social capital, which might place an undue burden on women as carers, or might result in new relationships of dependence or subservience. They qualify a near-romanticisation of pre-colonial social life with recognition of the 'dark side' of communal social capital.

Although the TSP framework recognises state and market failures, a case could be made for more emphasis on state action if social protection is to be seen as a 'common good'. Common goods are defined as those which individuals will not necessarily take care of, but which a government is normally mandated to provide. Putting reliance on communities could look like a signal to governments for abdication of responsibility. Community emphasis could also begin to look like the US model of welfare, in which the state essentially tells people to help themselves by 'pulling themselves up by their own bootstraps'. Then again, the harnessing of untapped community resources might be the only viable source of social protection for many vulnerable people.

\section{4 'Holistic' or too ambitious?}

The breadth of TSP, which covers everything from crisis-induced relief to transformative political action, seems to address almost all aspects of the development agenda. This is laudable, at least at the level of macro-theorising. It can be good, as we have seen, in attempting to bridge a humanitarian relief gap (though the neutrality principle must be grappled with). It also has the potential to plug gaps left by the market and the state. Indeed, Devereux and Sabates-Wheeler describe TSP as 'holistic', giving the framework a soothing, organic, 'everything's covered' tone.

But the framework may be trying to do too much. How applicable is it in practice? If an NGO took the framework and put it into operation, it would undoubtedly divide the framework into small projects for implementation. If you narrow the focus 
and cut TSP into pieces, its breadth is lost. This argument is not new, only another example in the macro vs. micro debate. The challenge will be in maintaining its macro breadth, while figuring out how to make TSP applicable. What combination of 'interventions' will equate to operationalising TSP in practice? And will TSP implementation share the problems typical of aid programming in terms of inadequate coordination?

Another challenge to TSP applicability is that transformation is necessarily long term, and true transformation requires more than token efforts. All too often in practice, awareness campaigns, for instance, are not strong enough or frequent enough to materialise change. The same is true for political lobbying for legislative reform. In the complexity of real-world political environments, it could take a long time to see effective policy change and then its effects in operation.

Finally, and reiterating comments above, even if policy change does happen, the vulnerable people it

\section{References}

Chambers, R. (1997) Whose Reality Counts? Putting the First Last, London: Intermediate Technology

Crisp, J. (2001) Mind the Gap! UNHCR, Humanitarian Assistance and the Development Process, UNHCR New Issues in Refugee Research, Working Paper 43, Geneva: United Nations High Commissioner for Refugees targets may not have been part of the agendasetting process.

\section{Conclusion}

The Transformative Social Protection framework is to be both commended and challenged: for its willingness to confront structural inequality by engaging in politics, for its inclusion of community and for its ambitious scope. Change is messy, and the power involved in lasting transformation can be both manipulated (by those in power) and manipulating (of those without it). Devereux and Sabates-Wheeler are right to note the 'dark side of social capital'. Dependence on communal systems can come with its own forms of marginalisation and dependence. Nonetheless, the people being 'transformed' should have more of a say in determining the transformative agenda. Reaching beyond ameliorative handouts, TSP is aiming to catalyse lasting change that makes the need for crisis-induced handouts less necessary, by targeting chronic vulnerability. Can TSP do it all? Watching the framework in practice will be the litmus test.

Devereux, S. and Sabates-Wheeler, R. (2004) Transformative Social Protection, IDS Working Paper 232, Brighton: IDS

Longley, C., Christoplos, I. and Slaymaker, T. (2006) Agricultural Rehabilitation: Mapping the Linkages Between Humanitarian Relief, Social Protection and Development, London: Humanitarian Policy Group at Overseas Development Institute 